\title{
Thigh circumference percentile curves for the UK child and youth population
}

\author{
H. D. McCarthy \\ Institute for Health Research and Policy, London Metropolitan University, Holloway Road, London N7 8DB, UK
}

There is growing evidence to suggest that thigh circumference (TC) is an independent measure of metabolic health in adults as recently demonstrated where a smaller TC was associated with the development of cardiovascular morbidity and early mortality ${ }^{(1)}$. Although there has been limited research on TC and health in children ${ }^{(2)}$, TC percentile charts are now appearing in the literature ${ }^{(3)}$. The objective of this study was to construct TC percentile curves for British children.

Secondary analysis of data on 8079 children (3502 boys, 4577 girls) aged 5-17 years collected in 1977 and 1987 (prior to the rise in obesity prevalence) was conducted. TC was measured to the nearest $0.1 \mathrm{~cm}$ around the top of the thigh immediately below the gluteal fold $^{(4)}$. Decimal age was recorded. Smoothed percentile curves for TC were constructed separately for boys and girls using the LMS $\operatorname{method}^{(5)}$

Figures 1 and 2 show the TC percentile curves for the 2nd, 9th, 25th, 50th, 75th, 91st and 98th percentiles (cm) for boys and girls, respectively. An age-related increase in TC followed a similar pattern between boys and girls with neither gender showing evidence of reaching a plateau at the upper end of the age range. Median values were consistently greater in girls from age 5 years. There was a suggestion of a pubertal effect on TC in girls, with them tending to show a steeper increase at approximately ages 11-13 years, whereas in boys, there was no obvious increase in the slope of the curves. The adult TC below which risk for CVD or premature death was increased, equated to approximately the 91 st percentile at age 16 years in this reference group.

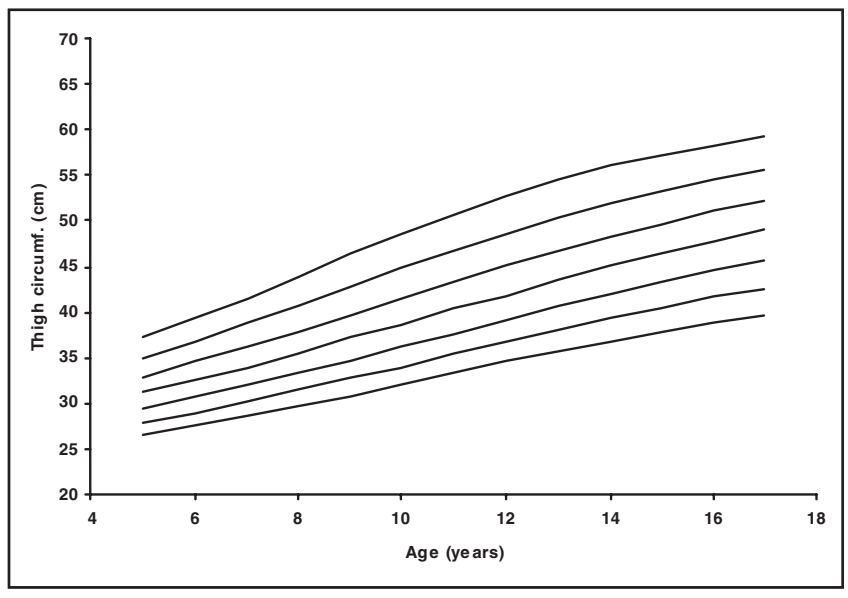

Fig. 1. Boys.

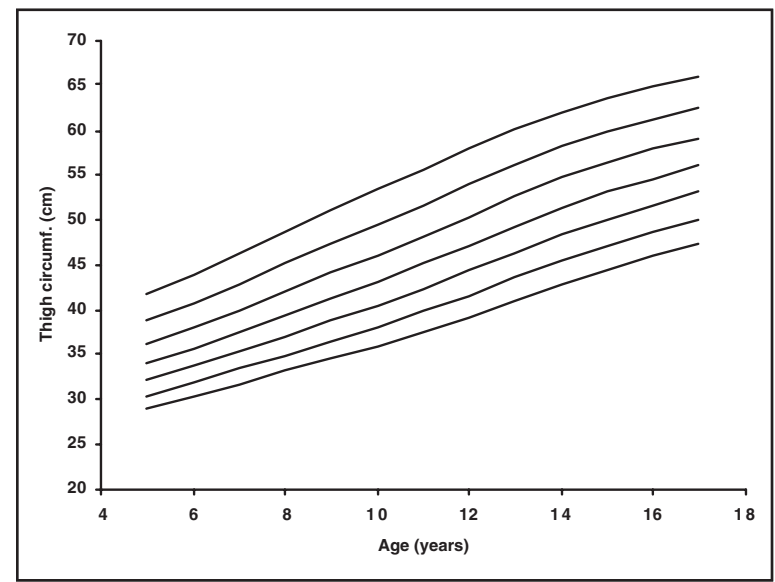

Fig. 2. Girls.

These curves represent the first of their kind in British children. They can be added to the suite of existing references for childhood growth and body composition. They will now allow calculation of individual SD scores for TC in current and future epidemiological studies that incorporate children's thigh measurement into body composition and metabolic health studies.

1. Heitmann BL \& Frederiksen P (2009) Br Med J 339, b3292.

2. Lassek WD \& Gaulin SJ (2007) Am J Phys Anthropol 133, 1147-1151.

3. Moreno LA, Mesana MI, Gonzalez-Gross M et al. (2007) Int J Obes 31, 1798-1805.

4. BSI (1990) Body Measurements of Boys and Girls from Birth up to 16.9 Years, BS7231. London: British Standards Institute.

5. Cole, TJ (1990) Eur J Clin Nutr 44, 45-60. 